\title{
INSCRIPCIONES ROMANAS DE SEGOVIA, IV: ADDENDA ET CORRIGENDA A EPIGRAFIA ROMANA DE SEGOVIA Y SU PROVINCIA
}

\author{
ROMAN INSCRIPTIONS OF SEGOVIA, IV: \\ ADDENDA ET CORRIGENDA TO \\ EPIGRAFÍA ROMANA DE SEGOVIA Y SU PROVINCIA
}

\author{
Juan Santos Yanguas ${ }^{1}$ y Ángel Luis Hoces de la Guardia Bermejo \\ UPVIEHU - Asociación de Amigos del Museo de Segovia \\ juan.santos@ehu.es \\ ORCID: 0000-0002-0377-1041 \\ hdg@hdgsg.net \\ ORCID: 0000-0002-9713-9206
}

DOI: $10.1387 /$ veleia.16987

Resumen: En este artículo presentamos nuestra cuarta aportación de novedades de la epigrafía de época romana en la provincia de Segovia, con cinco piezas añadidas (nuevas o ya publicadas) y cuatro como corrigenda.

Palabras clave: Segovia, Epigrafía latina, Cauca, Coca, Madrona, Saldaña de Ayllón.

Abstract: This paper is the fourth supplement to the Epigrafia Romana de la provincia de Segovia ('Roman epigraphy in the province of Segovia'). It offers five inscriptions which had not been included in the Epigrafia (and which are either new or have already been published) and introduces some comments on four further inscriptions.

Keywords: Segovia, Latin Epigraphy, Cauca, Coca, Madrona, Saldaña de Ayllón.

Recibido: 03-06-2016

Definitivo: 06-06-2016

Durante el proceso de puesta al día de la epigrafía romana de Segovia, que publicamos en 2005 con Javier del $\mathrm{Hoyo}^{2}$, junto a otras aportaciones y estudios onomásticos, se han hallado piezas nuevas por nosotros mismos o aportadas por otros ${ }^{3}$.

Además, aprovechando las obras realizadas dentro del "Proyecto de paso de inspección en la zona norte de la muralla de Segovia" y las del "Plan Director de la Muralla de la ciudad de Segovia", pudimos acompańar en diversas jornadas a la arqueóloga supervisora de los proyectos, D. ${ }^{\text {a }}$ Pilar Ba-

${ }^{1}$ Grupo de Investigación del Sistema Universitario Vasco IT760-13 y Proyecto de Investigación del Ministerio de Economía y Competitividad HAR 201565526-P.

2 Epigrafía romana de Segovia y su provincia, Segovia 2005.
${ }^{3}$ Además de estas aportaciones, han sido encontrados un árula dedicada a la diosa Epona y otra dedicada probablemente al dios Mercurio. Sobre cada una de estas piezas hay sendos trabajos en prensa en Segovia Histórica 2-3, 2015-2016. 
rahona Tejedor ${ }^{4}$, por lo que tuvimos ocasión de acercarnos a piezas de las que, por su ubicación, era imposible un análisis directo; esta actuación tuvo lugar entre septiembre y octubre de 2011. También la limpieza de paramentos dejó al descubierto alguna pieza nueva, como más adelante se irá especificando.

\section{$A D D E N D A$}

\section{CAUCA-CocA}

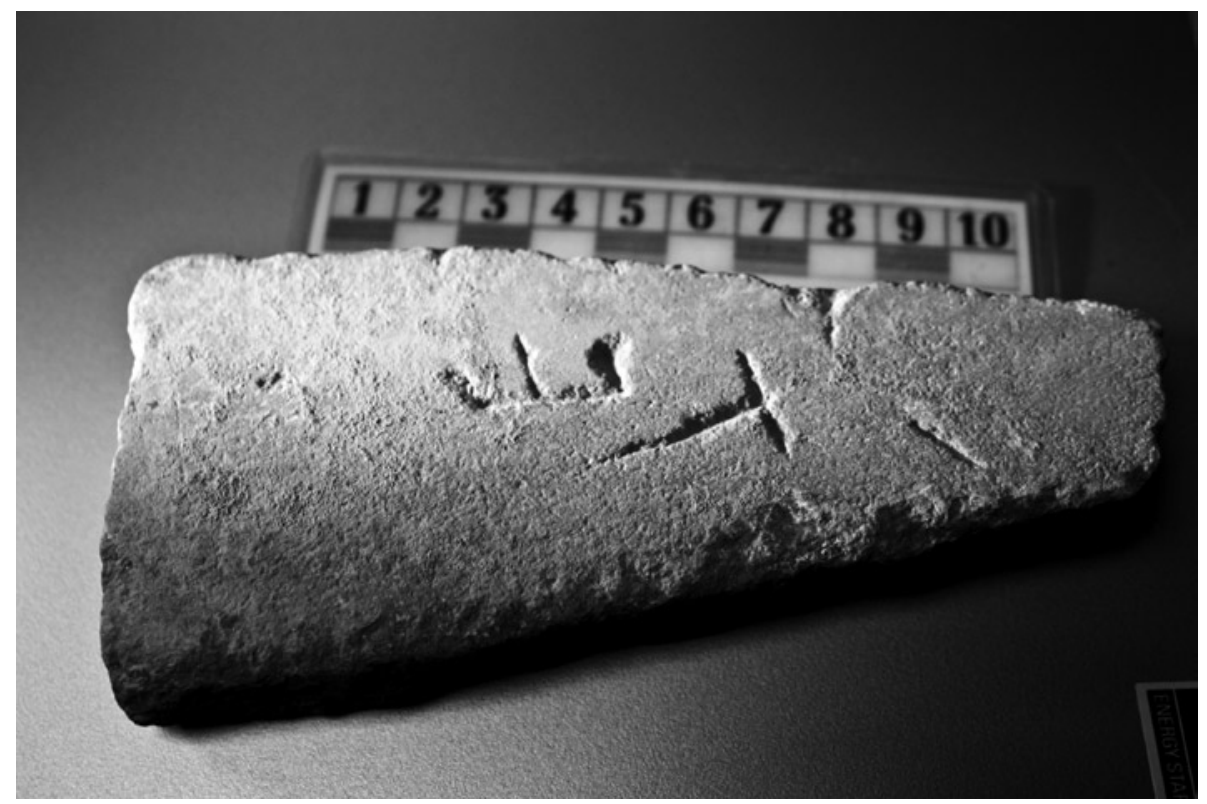

FOTо I.

Fragmento trapezoidal de una placa de mármol de color blanquecino hallado en Coca, Cauca, en el yacimiento de Las Pizarras, en la campaña arqueológica de 2005, dentro de un contexto heterogéneo (UE 1007), producto de la colmatación de una zanja bastante larga. Aún mantiene la capa de cal sobre la superficie de la pieza, como resultado de su amalgama con restos constructivos.

Tiene grabadas dos letras y el asta de lo que parece una tercera, sin formar una misma línea de texto evidente, pues presentan diferente orientación de lectura. No hay restos de campo epigráfico ni de decoración. En general presenta un buen estado de conservación, aparte de un pequeño desconchón en el lateral izquierdo a la altura del trazo de línea 1.

4 De nuevo le agradecemos el habernos permitido acompañarla, así como habernos facilitado datos sobre diversas piezas de la muralla de Segovia. 
Pudimos estudiarla en uno de los despachos de la Unidad de Arqueología de la IE University (Campus de Santa Cruz, Segovia), el 5 de diciembre de 2012, debido a la amabilidad del Dr. D. Cesáreo Pérez González.

Soporte: $(13) \times(6) \times 1,5 \mathrm{~cm}$.

Letras: Trazo $-0,5 ; \mathrm{T}-2,4 ; \mathrm{E}-2 \mathrm{~cm}$.

$\stackrel{+}{\mathrm{T}}$

Pérez, Reyes 2009: 45-47, no 10 (foto 3, en 61) ( $\rightarrow$ HEp 18, 2009: 296).

Letra capital alargada de trazo irregular, con una altura diferente en cada letra.

El trazo inclinado está completo. A su izquierda, en el borde, parece haber otro trazo, roto por la fractura. La $\mathrm{T}$ presenta los vástagos muy profundos, mientras que la $\mathrm{E}$, girada a izquierda e invertida, presenta el vástago inferior menos profundo que el resto de la letra y mal realizado.

Cabe la posibilidad de que, ya fragmentado, este trozo de placa de mármol haya sido utilizado para realizar pruebas de escritura. De ahí que las letras no estén grabadas con la misma orientación.

Por todo lo dicho podría pensarse en una datación a partir del siglo iII d.C. ${ }^{5}$.

\section{Madrona}

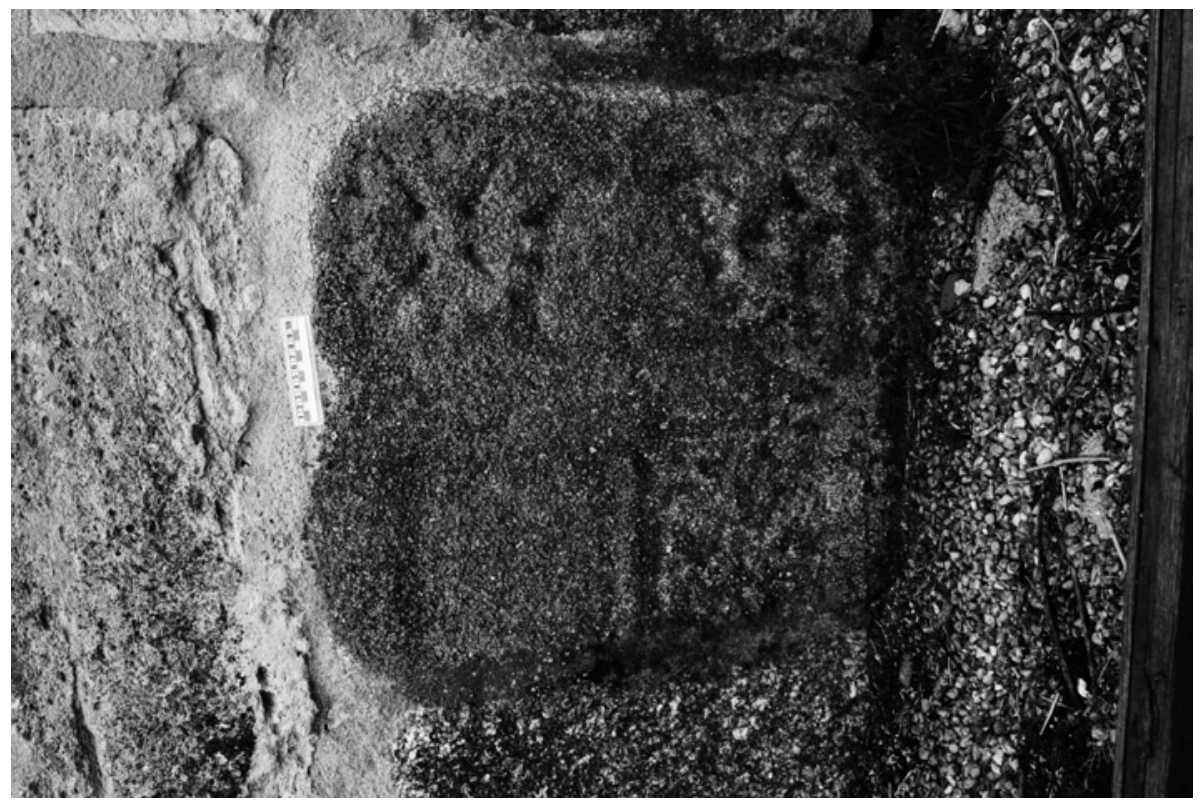

Fото 2.

5 Para $\operatorname{HEp}(18,2009,296)$, el empleo de una pieza de mármol incompleta retrasa su elaboración hasta casi el siglo $\mathrm{v}$ d.C. 
Como resultado de la visita de D. Jorge Santiago, que en noviembre de 2011 era el Arqueólogo Territorial de Segovia (en funciones), tuvimos notica de la existencia de esta estela empotrada en primera hilada en el lateral izquierdo de la iglesia parroquial de Nuestra Señora de la Cerca, junto a la cabecera, en Madrona ${ }^{6}$. Allí la examinamos y fotografiamos en julio de $2013^{7}$.

Estela de granito gris claro, con cabecera cuadrangular en la que se muestran dos rosetas tetrapétalas $(20 \mathrm{~cm} \varnothing)^{8}$ que enmarcan un simpulum; está tumbada a derecha y fracturada en la zona del pie, no conservado. Por debajo un listel de $9 \mathrm{~cm}$ de alto que separa un doble campo epigráfico enmarcado por molduras simples y rebajado con respecto al resto de la piedra; presenta restos de letras. El campo epigráfico izquierdo no parece conservar texto, si es que lo tuvo en alguna ocasión. El campo epigráfico derecho conserva restos de letras.

Soporte: $(62) \times 63 \mathrm{~cm}$.

Campo epigráfico izq.: $(22 / 19) \times 20 \mathrm{~cm}$.

Campo epigráfico dcho.: $(19 / 17) \times 20 \mathrm{~cm}$.

Letras: $3 \mathrm{~cm}$.

Espacios interlineales: $1 \mathrm{~cm}$.

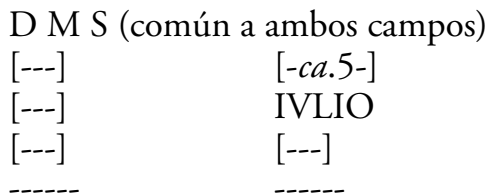

Inédita.

Letra capital de surco poco profundo, por lo que se hace difícil su lectura.

Iulius es nomen muy abundante tanto en la epigrafía hispana como en la imperial. En Segovia está documentado en seis ocasiones, una de ellas en la forma femenina en una inscripción de Segovia, hoy perdida ${ }^{9}$; de las otras cinco, dos en una misma inscripción rupestre que contiene una dedicatoria a Hércules en la margen derecha del río Riaza en Montejo de la Vega de la Serrezuela ${ }^{10}$, uno en $\operatorname{Coca}^{11}$ y otros dos en Segovia, en un caso en una inscripción perdida ${ }^{12}$.

Cronología: por la paleografía y la fórmula D.M.S. puede situarse a finales del siglo i d.C. o siglo II d.C.

${ }^{6}$ En las cercanías de la localidad de Madrona, población situada al S.O. de la ciudad de Segovia, de cuyo Ayuntamiento depende administrativamente, en la carretera N-110, a unos $8 \mathrm{Km}$. de la capital, se localizó una necrópolis de época visigoda, que fue excavada en 1951 por Antonio Molinero (Molinero 1952, 191-193 y 1971, lám. LXV-XCVI).

7 Damos las gracias nuevamente a D. Jorge Sowa, párroco de Madrona.
8 Sobre rosetas y elementos vegetales en la epigrafía romana de Segovia, véase ahora Santos y Hoces de la Guardia, 2014.

9 ERSg 179.

10 ERSg 54 a y 54 b.

11 ERSg 7.

12 ERSg 84; ERSg 180. 
Saldaña de Ayllón

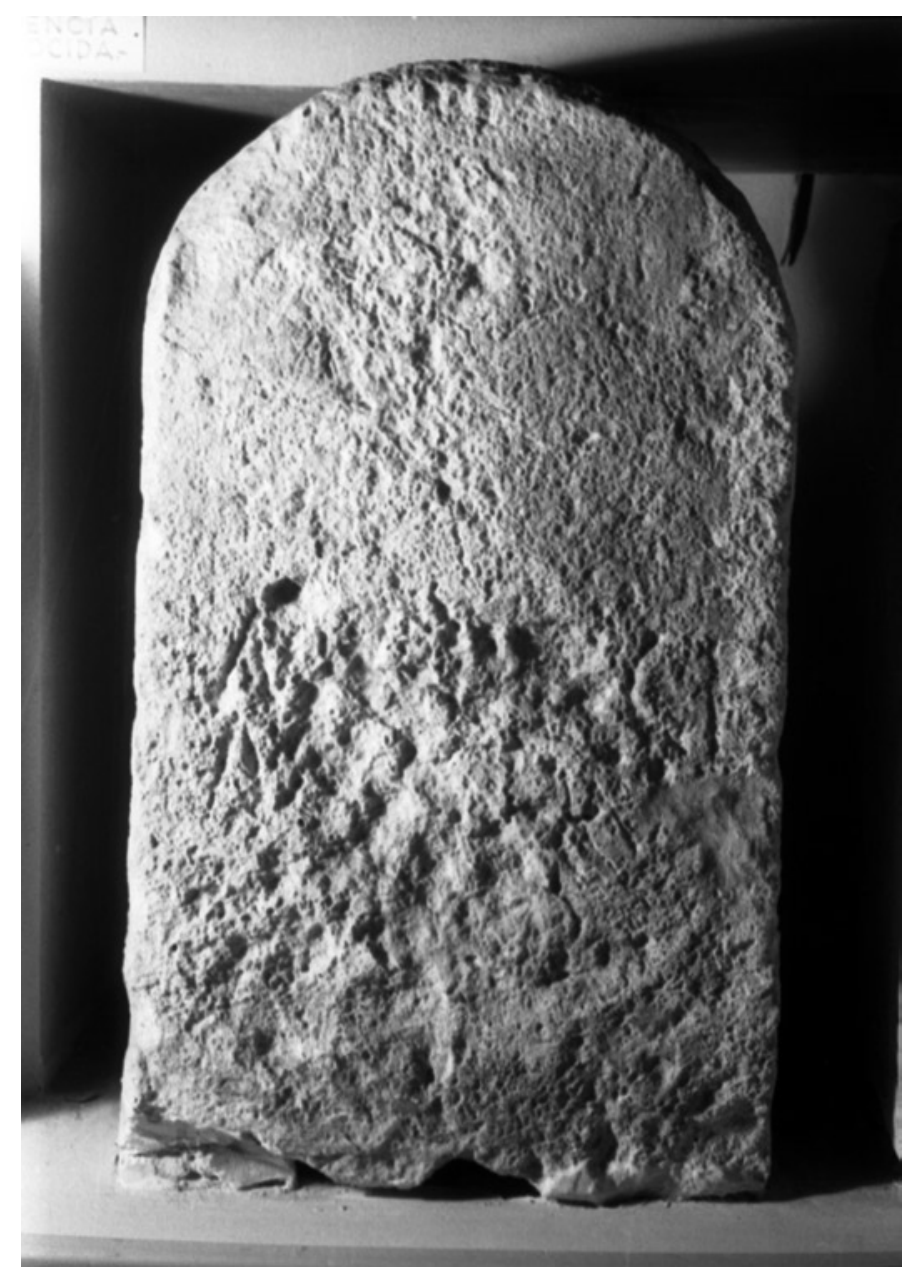

Fото 3. (Museo Arqueológico Nacional)

Localizada, al aparecer, en Riba de Saelices (Guadalajara), hay serias dudas sobre su procedencia y probablemente haya que ponerla en relación con las inscripciones $E R S g 58$ y 59, ambas también, como ésta (n. ${ }^{\circ}$ inv. 38372) ${ }^{13}$, depositadas en el Museo Arqueológico Nacional. Hernando afirma ${ }^{14}$ : "Según comunicación oral de J. Gómez-Pantoja, es muy posible que el marqués de Cerralbo se refiriese a esta inscripción en una carta enviada a Fita desde el Senado (con fecha 24-1-1916), en la que indicaba: «Además, le remito al mismo tiempo una fotografía de la inscripción que dije a V. se ha hallado junto a mis excavaciones» [con una nota explicativa a mano]: "la inscripción se encontró en Saelices (Guadalajara), en la inmediación de excavaciones mías, pero no en éstas»".

13 Damos las gracias al Departamento de Documentación del M.A.N. por facilitarnos la fotografía que acompaña, así como el permiso de publicación. Ha sido descrita a la vista de fotografía al no haber podido acceder directamente a la pieza.

${ }_{14}$ Hernando apud HEp 17, 2008, 45-46, no 78. 
Gimeno" ${ }^{15}$ dice que "Da la casualidad de que la cognatio mencionada en una de las aras dedicadas a Arco es Medugenicum ${ }^{16}$, hecho que habla más a favor de la procedencia de las aras de Riba de Saelices y no de Saldaña de Ayllón en Segovia (...), cuando, además, toda la argumentación a favor del traslado se basa en un apunte de F. Fita en el reverso de una fotografía".

Hernando ${ }^{17}$, por su parte, afirma que "No se puede negar la propuesta del profesor GómezPantoja señalando que su argumentación se basa sólo en el apunte autógrafo de F. Fita que consta en el revés de la fotografía de dicha pieza («Saldaña (Segovia) 1917»), porque es precisamente el hecho de que el testimonio procede de Fita, y no de otro autor, lo que confiere veracidad a la noticia, la única clara y explícita con respecto al lugar de procedencia de la misma", y añade más adelante que "En cualquier caso, la presencia de un Medugenus en el testimonio inédito que aquí se presenta y de un genitivo de plural Medugenicum en el altar citado no sólo no proporciona ningún argumento válido para optar por una u otra procedencia, sino que, de hacerlo, bien podría entenderse a la inversa, esto es, para señalar que todas la piezas proceden de Saldaña de Ayllón, no de Riba de Saelices".

Estela caliza con cabecera redondeada, sin ningún rastro de decoración. El campo epigráfico parece estar delimitado por moldura redondeada poco resaltada. Se halla fragmentada en su zona inferior. La conservación es deficiente. Está depositada en el Museo Arqueológico Nacional.

Soporte: $62 \times 36 \times 19 \mathrm{~cm}^{18}$.

Campo epigráfico: sin datos.

Letras: $5,5 \mathrm{~cm}$.

Espacios interlineales: sin datos.

MEDVCE

NVS $\cdot$ RV

$+++\mathrm{VS}$

Transcripción: Meduce/nus Ru/[fin]us.

Traducción: Meduceno Rufino.

Gimeno 2008, 281, nota $82(\rightarrow H E p$ 17, 2008, 78).

Aparato crítico: L.1-4? Medu/genus Ru/finus D[-1-2-] / [------?] Stylow apud Gimeno ${ }^{19}$.

Meducenus/Medugenus es nombre indígena basado en el radical * $m e d^{b} u$ - 'miel, hidromiel', más el componente -genus, con sorda - $k$ - en el caso de Meducenus, representado en toda la Celtiberia ${ }^{20}$. La traducción del nombre es 'nacido de la hidromiel' > 'hijo de la hidromiel'21. Derivado de este nombre se documenta también en Saldaña de Ayllón el grupo de parentesco Meducenicum (ERSg 127-129, n. $\left.{ }^{\circ} 58\right)$.

15 Gimeno 2008, 281, nota 82.

16 Véase ERSg, 127-129, n. ${ }^{\circ} 58$.

17 Hernando apud HEp 17, 2008, 46-47.

$1862 \times 36 \times 19 \mathrm{~cm}$ según María Ángeles Castellano (M.A.N.) en correo electrónico; $60 \times 35 \times 18 \mathrm{~cm}$ según Gimeno 2008, 281, nota 82.
19 Lectura de A. U. Stylow según calco, publicada por Gimeno, 2008.

20 Véase Pokorny, IEW, 707; Albertos 1966,153; Vallejo 2005, 356-359.

21 Véase Gorrochetegui 1994, 311. 
Rufinus es cognomen muy documentado tanto en Hispania como en el resto del imperio ${ }^{22}$. Kajanto ${ }^{23}$ lo recoge entre sus cognomina referidos a 'partes del cuerpo: peculiaridades físicas: color del pelo': rubio. Parece derivado del cognomen Rufus, con el mismo significado.

Cronología: la brevedad del texto y los antropónimos en nominativo quizás estén apuntando al siglo i d.C. La paleografía nos ayuda poco en este caso, al estar tan borrado el texto, aunque la forma alargada de las letras puede llevarnos, al menos, a la primera mitad del siglo II d.C.

\section{SEgOVIA}

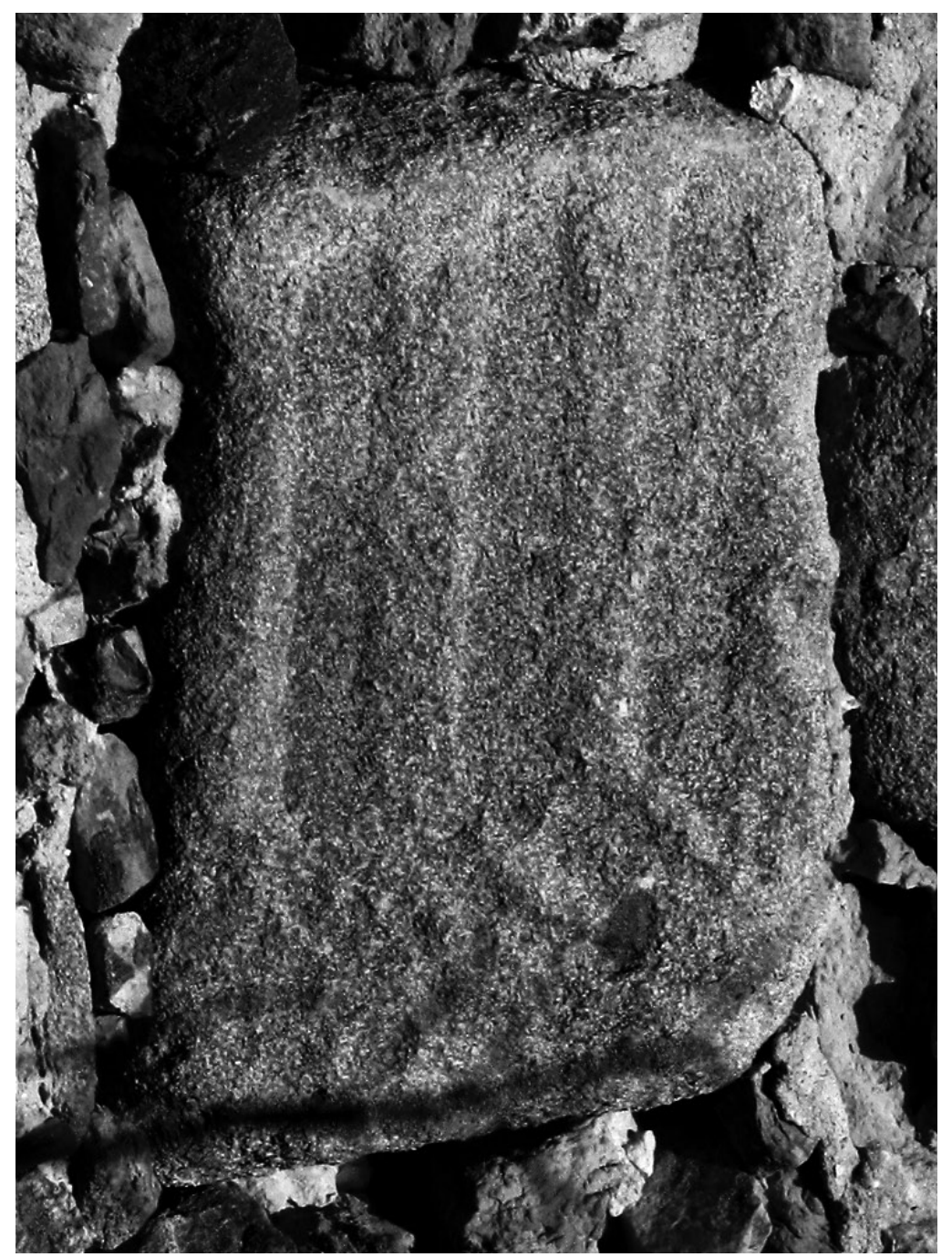

Fото 4

22 Abascal 1994, 486-487; OPEL IV, 2002, 33-34.
23 Kajanto 1965, 229 ( $\rightarrow$ Solin y Salomies 1994, 393). 
Se halla empotrada en el lienzo $28^{\prime 24}$, a unos cuatro metros de altura tumbada a izquierda, en la curva del Paseo de Santo Domingo de Guzmán, en el lienzo de la casa de los Lozoya.

Probable estela de granito gris, en la que, como motivo decorativo, se muestran tres arcos de 'puertas del cielo' similares a los que se documentan en ERSg 111, 112 y 123. Está fragmentada, conservándose sólo la parte inferior de la pieza, por lo que no tiene ni cabecera ni cartela; le falta también el lateral derecho por fractura.

Soporte: $(c a .80) \times(c a .60) \mathrm{cm}$.

Sin texto conservado.

Inédita.

Cronología: No parece posible fecharla.

\section{SEgovia}

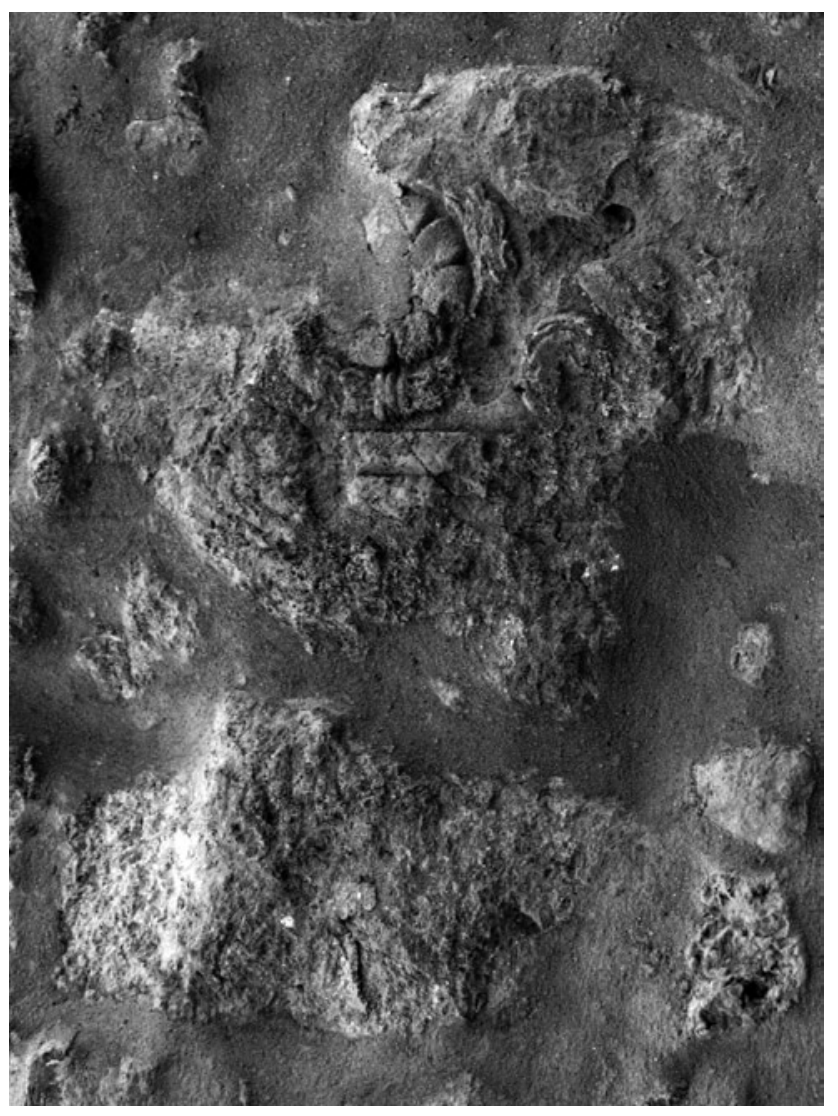

Fото 5

${ }^{24}$ En el año 2007, el Ayuntamiento de Segovia presentó el documento titulado "Plan Director de la Muralla de la ciudad de Segovia", firmado por el arquitecto D. Pablo Fernández-Longoria. En este plan se pretende la protección del monumento, la mejora del conocimiento histó- rico de la muralla y de la ciudad, la comprensión de la muralla y su entorno, y su difusión y puesta en valor. Además en los planos realizados se ha establecido una nueva numeración de los torreones y, por consiguiente, de los lienzos entre ellos. Esta numeración es la que seguimos aquí. 
Descubierta en el otoño de 2011 por P. Barahona durante las obras de consolidación de la muralla, en el torreón 58 de la misma, en la zona de la Puerta de Santiago, justo por encima de ERSg 113, tumbada a derecha.

Estela de caliza rojiza con cabecera recta, muy fragmentada en sus cuatro lados; la superficie está muy deteriorada. Se encuentra partida en dos trozos. Aparentemente ambos trozos encajan, aunque de su colocación en el muro no se puede deducir si falta algún trozo en esta parte. Si faltara algún trozo, estaríamos hablando de, al menos, tres líneas de texto, aunque de muy difícil lectura y con bastante separación entre ellas. En la cabecera se conserva una rosa decapétala $(20 \mathrm{~cm} \varnothing)$, a la que le faltan cuatro pétalos, en el centro, enmarcada por una corona de laurel, con un nudo bien tallado. En el espacio restante de la cabecera hay restos de decoración de difícil clasificación por estar muy erosionados, pero similar a la existente en la pieza $E R S g 88^{25}$.

Campo epigráfico enmarcado por doble moldura lisa, de la que quedan pocos restos, por lo que no se pueden aportar medidas fiables.

Soporte: $(78) \times(45) \mathrm{cm}$.

Letras: $5 \mathrm{~cm}$.

Espacios interlineales: difíciles de apreciar en el estado actual de la pieza.

$$
\begin{aligned}
& {[---]+++++[---]} \\
& \text { (rotura del soporte) } \\
& {[---]++ \text { DO+++Q̣[--- }}
\end{aligned}
$$

Inédita.

Letra capital alargada, aunque muy difícil de identificar dado su estado actual. Sólo son reconocibles claramente 2 letras en línea 2 de las conservadas.

Cronología: el tipo de decoración en la cabecera parece que puede permitirnos fecharla a finales del siglo I d.C. o inicios del siglo II.

\section{CORRIGENDA}

\section{SEgOVIA}

Debido a las obras en la muralla medieval de Segovia, mencionadas más arriba, pudimos utilizar los andamios para analizar directamente piezas ya publicadas, pero de muy difícil acceso por la altura a la que están colocadas.

25 Sobre rosas y rosetones ver ahora Hoces de la Guardia, Santos 2014, 140. 


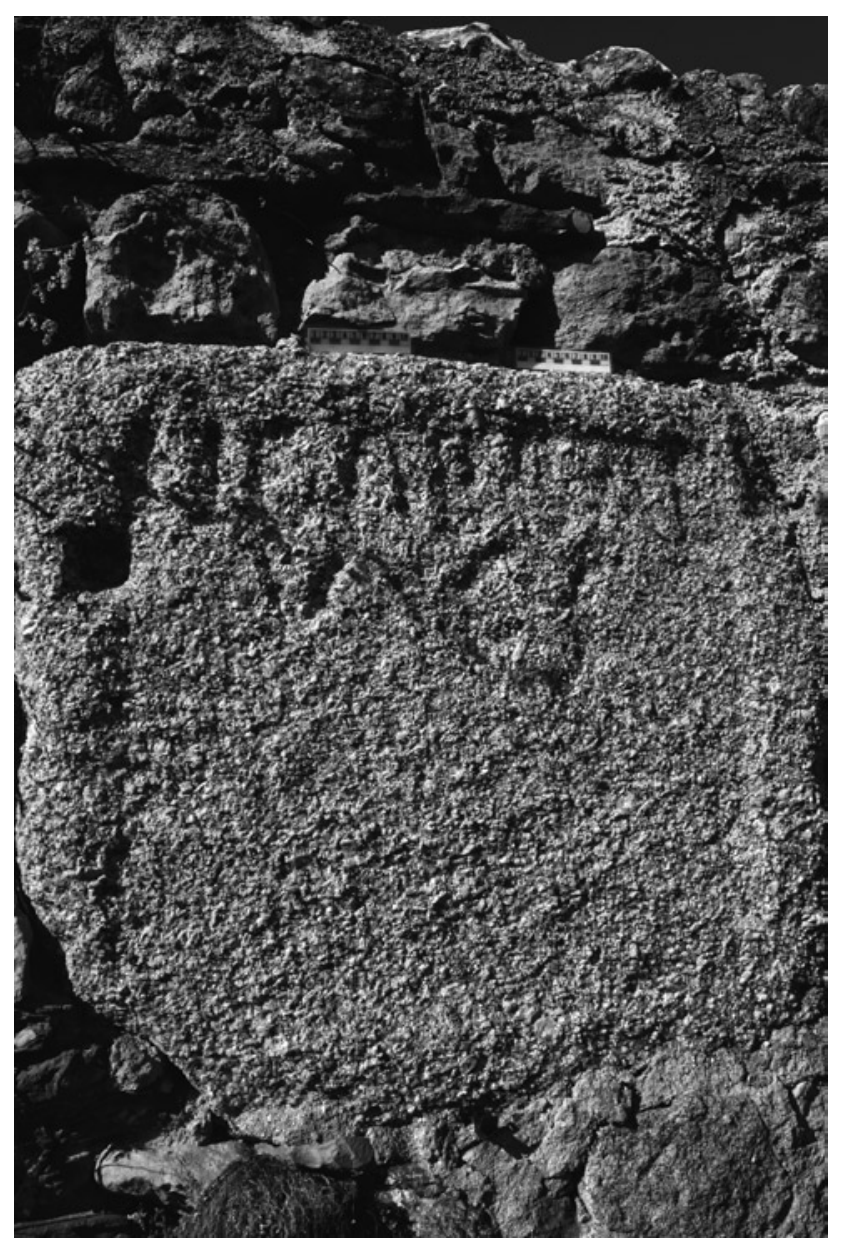

Fото 6.

En ERSg 140 se recoge un bloque de granito gris oscuro sin elementos decorativos y con el campo epigráfico delimitado por moldura redondeada y rebajado. Se halla empotrado en el lienzo 28' de la muralla medieval de Segovia, reutilizado como parte del murete de cierre de los jardines de San Juan de los Caballeros, en la plaza de Colmenares, en un lugar muy elevado (penúltima hilada). Ahora podemos aportar las medidas de la pieza.

Soporte: $72 \times 80 \times \pm 57 \mathrm{~cm}$.

Letras: $6 \mathrm{~cm}$.

Espacios interlineales: $3,5 \mathrm{~cm}$.

Hay grabada una línea con el texto VCABBAE y en la segunda un ininteligible VACS con VA en $\operatorname{exo}^{26}$.

26 En IRSg 140 habíamos propuesto una segunda línea $\mathrm{V}_{+++}$. 
SEgovia

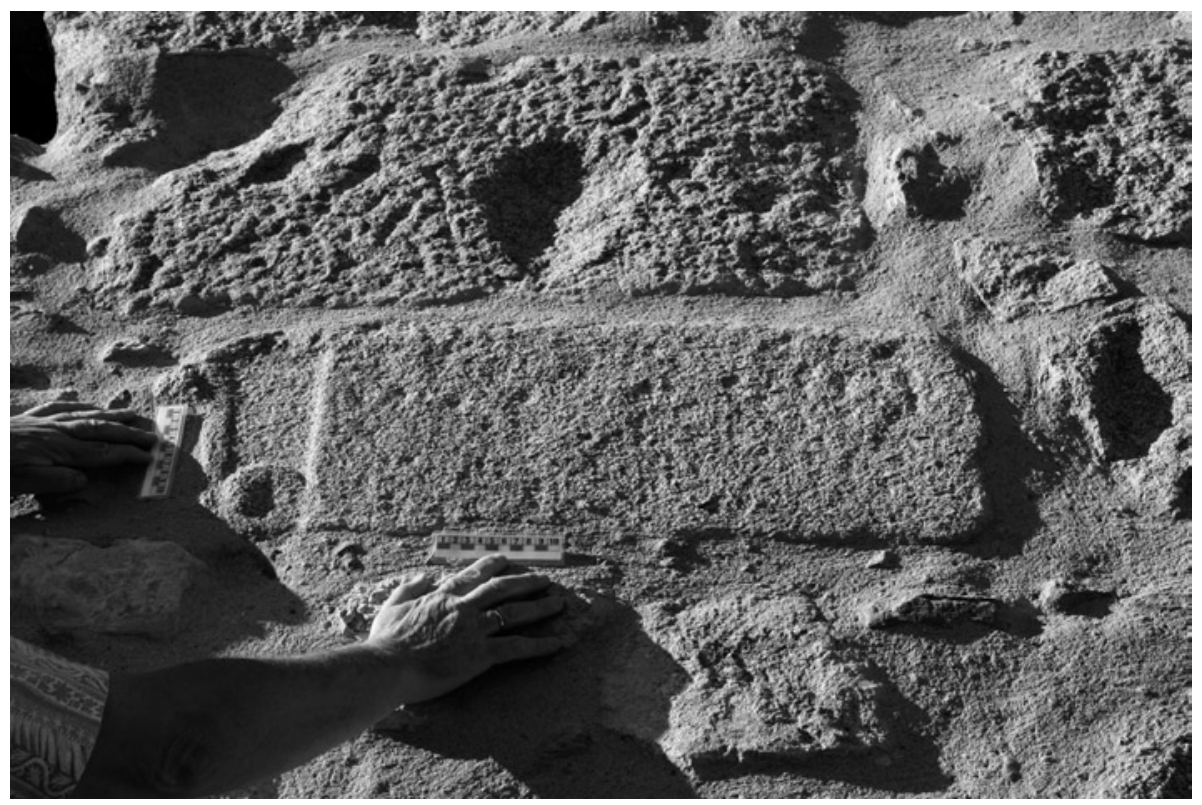

Fото 7 .

Hallada en 1980 por R. Knapp en su sección D, se encuentra empotrada en el lienzo (30)-31, a unos 35 metros a la izq. del Postigo de San Juan, a $180 \mathrm{~cm}$ del suelo de roca en que se apoya la muralla, en cuarta hilada, tumbada a la derecha; según este autor ${ }^{27}$ presenta una gran rosa hexapétala como motivo ornamental. Está recogida en ERSg 141. Siguiendo a Knapp, se hablaba allí de una estela de granito gris, rota por el lado derecho.

Aunque en ERSg, a pesar de no haberla localizado, la recogíamos como romana, el análisis directo de la misma, posible por el uso de los andamios de la intervención de la muralla, nos permite proponer que no se trata del soporte de una inscripción romana y que, además, posiblemente sean restos de un elemento arquitectónico, quizás una ventana.

\section{Ventosilla y tejadilla}

En ERSg 167 (Ventosilla y Tejadilla) habíamos propuesto la siguiente lectura para el campo epigráfico a): Licinio Antillico, an(norum) IV, / Ma[t]e[r]na Cilisio / p(osuit).

Hernando (apud HEp 14, 2005, 311) apunta que podría pensarse en una lectura Materna Cilisiq(um) en lugar de Materna Cilisio, es decir, dos únicos personajes, difunto y dedicante.

En un nuevo análisis directo de la pieza, hemos comprobado que Hernando tiene razón, pues, evidentemente, allí se aprecia la $\mathrm{Q}$, con trazo recto hacia abajo, que no habíamos visto en análisis anteriores. Cilisiqum se basaría en el nombre Cilisius, que se documenta en filiación en Granadilla (Cáceres). La estructura onomástica es, pues, NP+G.

\footnotetext{
27 Knapp, 1992, 255, n.o 284.4, lám. 51 microficha.
} 
Tras esta corrección, la lectura quedaría así: Licinio Antillico, an(norum) IV, / Ma[t]e[r]na Cilisiq(um) / p(osuit).
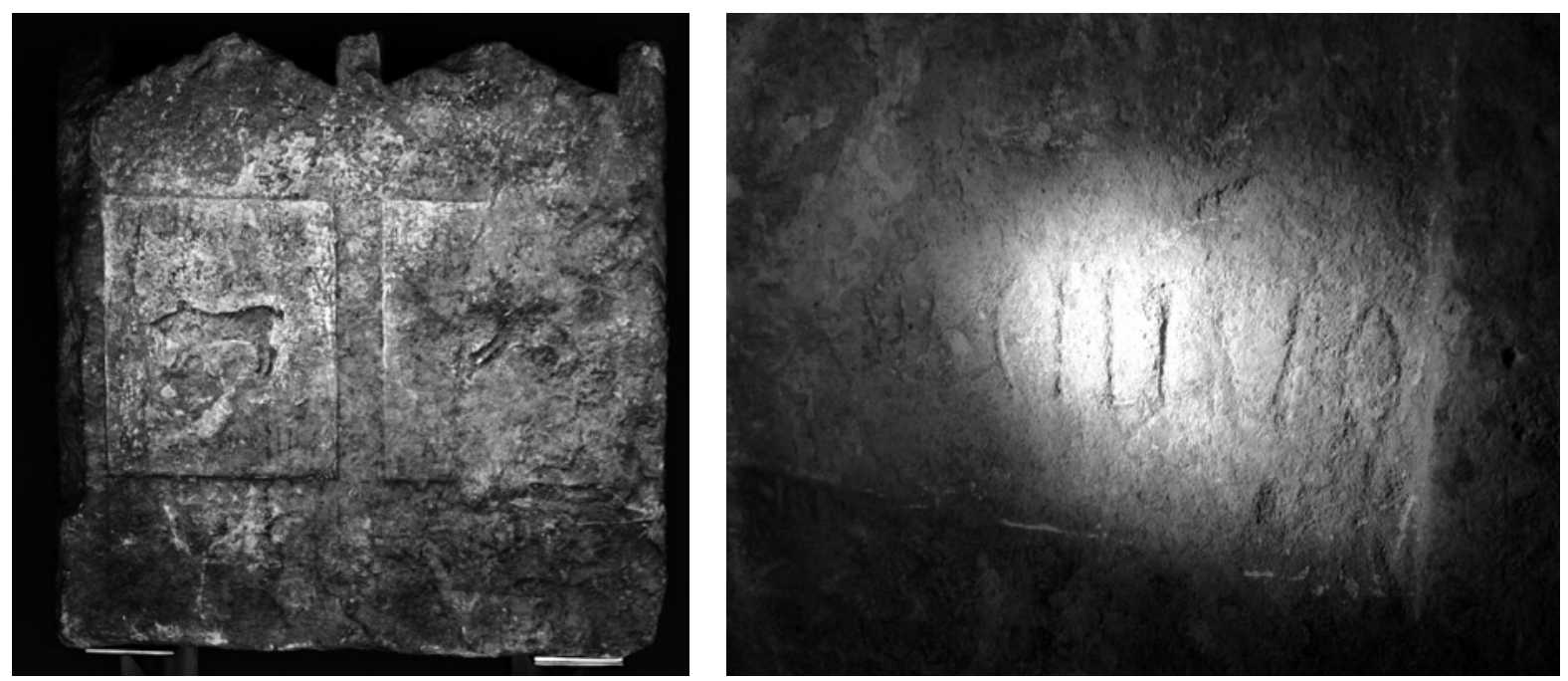

Foтоs 8 А ч в.

\section{Abreviaturas}

AE = L'Année Epigraphique

$E R S g=$ Epigrafía romana de Segovia y su provincia

$H E p=$ Hispania Epigraphica

$I E W=$ Indogermanisches Etymologisches Wörterbuch

OPEL = Onomasticon Provinciarum Europae Latinarum

\section{BiBLIOGRAFÍA}

Abascal Palazón, J. M., 1984, Los nombres personales en las inscripciones latinas de Hispania, Murcia.

Albertos Firmat, Ma L., 1966, La onomástica personal primitiva de Hispania: Tarraconse y Bética, Salamanca.

Gimeno Pascual, H., 2008, «Paisajes epigráficos en el espacio romano de la comunidad de CastillaLa Mancha», en: G. Carrasco Serrano (coord.), La romanización en el territorio de Castilla-La Mancha, Cuenca, 261-338.

Gorrochategui Churruca, J., 1994, "El celtibérico, dialecto arcaico celta», Emerita 62,2, 297-324.

Hoces de la Guardia Bermejo, Á. L., Santos Yanguas, J., 2014, «La decoración vegetal y las rosas y rosetones en los epígrafes segovianos de época romana», Segovia Histórica 1, 133-142.

Kajanto, I., 1965, The Latin Cognomina, Helsinki.

Knapp, R. C., 1992, Latin Inscriptions from Central Spain, Classical Studies 34. University of California Press. Berkeley-Los Angeles. 
LöRINCZ, B. (ed.), 2002, Onomasticon Provinciarum Europae Latinarum, vol. IV: QVADRATA - ZVRES, Lörincz, B. (ed.), Viena.

Molinero Pérez, A., 1952, «Una nueva necrópolis visigoda en la provincia de Segovia», AEspA 25, $191-$ 193.

—, 1971, Aportaciones de excavaciones y hallazgos casuales (1941-1959) al Museo Arqueológico de Segovia, Excavaciones Arqueológicas en España no 72, lám. LXV-XCVI.

Pérez González, C., Reyes Hernando, O., 2009, «Epigrafía caucense», Oppidum 5, 39-64.

Pokorny, J., 1959, Indogermanisches Etymologisches Wörterbuch, Berna, Munich.

Santos Yanguas, J., Hoces de la Guardia Bermejo, Á. L., Del Hoyo Calleja, J., 2005, Epigrafía romana de Segovia y su provincia, Segovia.

Solin, H., Salomies, O., 1994, Repertorium nominum gentilium et cognominum Latinorum, Hildesheim, Zurich, Nueva York.

Vallejo Ruiz, J. M.a, 2005, Antroponimia indigena de la Lusitania romana, [Anejos de Veleia, Series Minor 23], Vitoria-Gasteiz. 